\title{
RELATION OF A CENTRAL BANK TO THE ELASTICITY OF THE CURRENCY
}

\author{
By Jасов H. Sсhiff,
}

Senior member of the firm of Kuhn, Loeb \& Company, New York.

The storm which has recently broken loose has not yet entirely subsided. The causes of the financial trouble which has come upon us are hardly understood yet, but with typical American courage, we are looking already for the remedies, not only to retrieve what has been lost, but also in the desire to gain protection for the future against the recurrence of a disaster similar to that which has overtaken us.

The physician who would want to find proper remedies must first know and understand the origin and seat of disease. We should therefore, carefully inquire into the causes of this crisis, which has come upon us almost in the midst of an era of unprecedented prosperity.

To me it appears the answer is not surrounded by much doubt. The origin of the crisis is to be sought mainly in too great an expansion of enterprise of every nature, both corporate and individual. This, as a consequence, caused a straining of financial requirements, and particularly of credit, beyond legitimate limits. "Prosperity run riot," expresses perhaps best the condition, which existed and which brought us to our present plight. Nothing is probably more largely responsible for the breakdown, than the obstinacy with which new enterprise was fostered; in the enormous volume of business which was developed in every quarter, even in the face of a steadily increasing money scarcity, and, further, in the stubbornness with which it was insisted that the country was so prosperous and rich that particular caution and prudence were not needed, the march forward was made with a totally unprotected rear.

Look only at the number of so-called trust companies, called into being during recent years, which under a false flag bid for and attracted millions upon millions of deposits, to be used not for legitimate banking, but for illegitimate promotion, from which 
funds could not be withdrawn when their return was asked for by those to whom they belonged. And not alone in financial quarters had developed this prosperity madness-in industry and commerce, prudence had likewise been thrown to the winds. The manufacturer or merchant, when warned that he was expanding too rapidly - that he was straining his credit in too great an extremescornfully rejected the advice to go at a slower pace. His answer almost invariably was that the demand for his goods was great; that his customers were in good condition, and that anxiety and complications existed only in Wall Street. He overlooked the fact that the basis of the large volume of business, which he thought he was doing legitimately, rested, to a great extent, upon the very over-expansion of enterprise represented by the inflation of corporate securities he was criticising, and that the collapse in securityvalues would have inevitably to be followed by a breakdown of the general business of the country.

And now, as a panacea for the ills under which we are suffering, a sudden demand has sprung up throughout the country for currency reform. Proposed by the few who foresaw and foretold what was coming, as a partially protective measure, the warning to reform the currency was, when it was sounded, decried as a scheme of banks and bankers for selfish purposes, and became almost lost, like a cry in the wilderness. Had it been heeded, the present crisis might not have been entirely prevented, but it would never have gone so far in upsetting the business of the entire country. Let it be said, however, and well understood, at this juncture, that currency reform, imperatively needed though it is, can in itself never furnish protection against the consequences of unsound and illegitimate business methods. A properly constituted circulating medium, can furnish in times of financial difficulty a palliative, but without simultaneous reform in the unsound practices, which, to so considerable an extent, have governed the affairs of financial institutions, currency reform will be of little avail.

The Governor of the State of New York, with statesmanlike sagacity, has just taken action with a view to correct the shortcomings, which have been laid bare. A commission has been authorized which is to report upon a revision of the banking laws of the state, action such as this should be particularly welcomed.

I shall not enter here into a discussion of any particular scheme 
for the reform of the currency, to that I have already furnished my quota upon earlier occasions. So much has already been said, written and published upon the question of currency reform, so many propositions have been made by all sorts and conditions of men as to methods, ways and means, through which is to be secured what is needed, that with the meeting of Congress just upon us, it had perhaps now best be left to the wisdom of our national legislators to embody some measure into the form of law, which to them shall appear to best satisfy the demands and needs of all sections of the country. Congress will, in any event, have at its disposal rather a long catalogue of currency reform plans to select from.

What we are most in need of at this juncture, is the enactment of a measure, through which the circulating medium can be made to respond promptly to a diminished money demand. We have, during recent years, with the enormous expansion in enterprise and general business, no less than in the few weeks since this crisis has come upon us, been rather liberal in the creation of paper currency. If we are not careful, we shall before long find ourselves face to face with so large a volume of paper money, that gold will inevitably be driven out. Otherwise, some day, when this mass of paper can no longer be digested, we may be face to face with a depreciation in the standard of credit of the government, as expressed by the market value of United States bonds.

Expansion of the currency, when legitimately needed, will, under proper provision for this, take care of itself, if only in any scheme for the reform of the currency, proper provision be first made for the promptest possible contraction of the circulating medium, when its volume becomes too large for legitimate requirements. Nor is it likely that any scheme for the issuance of a circulating medium will prove permanently satisfactory, which shall clothe 6,000 banks with the privilege of issuing credit currency, each for itself. No matter how completely the safeguards proposed to be established through the creation of a guarantee fund may appear to be thrown around the exercise of this privilege, a single default, even if only temporary, would likely create prejudice against the entire volume of the outstanding currency, and no chances, however remote, ought to be permitted to be taken in this respect. Whether it shall be a central bank-if authority for the establishment of such 
can be obtained-or a central association of national banks, to possess no other function than to issue to the banks the circulating notes, to which, under the stipulations and restrictions to be imposed by law, they shall become entitled, there is needed a central authority, to properly control and determine the issuance of any circulating medium, based upon assets. Such a controlling central authority should and can best be constituted by the banks themselves. An association of national banks would, for the time being, at least, probably prove more acceptable and practicable than a central bank. The latter, to be of real advantage, would not only have to receive a monopoly of the privilege of issuing circulating notes, but would moreover have to become the depository of the funds of the government. It would have to undertake the discounting of commercial paper, both for banks and for individuals, and it is not likely that the country is, at this time, prepared to sanction so far-reaching a scheme, which of necessity would revolutionize our entire national banking system.

The one lesson, at least, which we should learn from recent experiences, is that the issuing of clearing-house certificates in the different bank centers, while no doubt it helped locally, has also worked considerable harm. It has broken down domestic exchanges and has paralyzed to a large extent the business of the country. Far better, as has recently been semi-officially proposed, that the government itself should become authorized to issue, in times of great stress, legal-tender loan certificates through the clearing houses, to the banks, upon appropriate security, and with stringent automatically acting provision for quick redemption. Undesirable as such an expedient may be in itself, from an economic point of view, it would at least prevent a breakdown of domestic exchanges, such as we have just experienced, resulting in a large premium upon currency-or, to state it more correctly, in a large discount upon bank checks. We have seen how the suspension of cash payment by the banks in the leading centers, compelled us to throw upon Europe the burden of financing our cash requirements almost entirely during the important period of the crop movement, and forced the Bank of England into a position, so mortifying for us, where it had to assume this burden almost single-handed.

Comparisons are odious, but sometimes they are also profitable, if properly applied. Let us at least hope that the severe and costly 
lessons we have received, shall not be permitted to be forgotten, until we have found appropriate remedies. It is certain, if this be done, we shall emerge from the momentous period, through which we are just passing, freed from many handicaps, which still impede us in the financial, commercial and industrial aspirations which we possess-fortunately be it said-both as a nation and as individuals. 